\title{
Is the superbug fungus really so scary? A systematic review and meta-analysis of global epidemiology and mortality of Candida auris
}

Jingjing Chen ${ }^{1,2,3 \dagger}$, Sufei Tian ${ }^{1,2,3 \dagger}$, Xiaoxu Han ${ }^{1,2,3 \dagger}$, Yunzhuo Chu ${ }^{1,2,3}$, Qihui Wang ${ }^{1,2,3}$, Baosen Zhou ${ }^{4}$ and Hong Shang ${ }^{1,2,3^{*}}$ (D)

\begin{abstract}
Background: Candida auris is a new pathogen called "superbug fungus" which caused panic worldwide. There are no large-scale epidemiology studies by now, therefore a systematic review and meta-analysis was undertaken to determine the epidemic situation, drug resistance patterns and mortality of $C$. auris.

Methods: We systematically searched studies on the clinical report of Candida auris in Pubmed, Embase and Cochrane databases until October 6, 2019. A standardized form was used for data collection, and then statics was performed with STATA11.0.

Results: It showed that more than 4733 cases of $C$. auris were reported in over 33 countries, with more cases in South Africa, United States of America, India, Spain, United Kingdom, South Korea, Colombia and Pakistan. C. auirs exhibited a decrease in case count after 2016. Clade I and III were the most prevalent clades with more cases reported and wider geographical distribution. Blood stream infection was observed in $32 \%$ of the cases, which varied depending on the clades. Resistance to fluconazole, amphotericin B, caspofungin, micafungin and anidulafungin in C. auris were $91,12,12.1,0.8$ and $1.1 \%$. The overall mortality of C. auris infection was 39\%. Furthermore, subgroup analyses showed that mortality was higher in bloodstream infections (45\%), and lower in Europe (20\%).

Conclusions: Over 4000 cases of C. auris were reported in at least 33 countries, which showed high resistance to fluconazole, moderate resistance to amphotericin B and caspofungin, high sensitivity to micafungin and anidulafungin. The crude mortality for BSI of C. auris was $45 \%$ which was similar to some drug-resistant bacteria previously reported. In conclusion, C. auris displayed similar characteristics to some drug resistance organisms. This study depicts several issues of $C$. auris that are most concerned, and is of great significance for the clinical management.
\end{abstract}

Keywords: Candida auris, Case count, Drug resistance, Mortality, Bloodstream infection, Clade

\footnotetext{
* Correspondence: hongshang100@hotmail.com

${ }^{\dagger}$ Jingjing Chen, Sufei Tian and Xiaoxu Han contributed equally to this work.

'Department of Laboratory Medicine, the First Affiliated Hospital of China

Medical University, No. 155, Nanjing North Street, Heping District, Shenyang

110001, Liaoning, China

${ }^{2}$ National Clinical Research Center for Laboratory Medicine, the First Affiliated

Hospital of China Medical University, Shenyang 110001, China

Full list of author information is available at the end of the article
}

(C) The Author(s). 2020 Open Access This article is licensed under a Creative Commons Attribution 4.0 International License, which permits use, sharing, adaptation, distribution and reproduction in any medium or format, as long as you give appropriate credit to the original author(s) and the source, provide a link to the Creative Commons licence, and indicate if changes were made. The images or other third party material in this article are included in the article's Creative Commons licence, unless indicated otherwise in a credit line to the material. If material is not included in the article's Creative Commons licence and your intended use is not permitted by statutory regulation or exceeds the permitted use, you will need to obtain permission directly from the copyright holder. To view a copy of this licence, visit http://creativecommons.org/licenses/by/4.0/. The Creative Commons Public Domain Dedication waiver (http://creativecommons.org/publicdomain/zero/1.0/) applies to the data made available in this article, unless otherwise stated in a credit line to the data. 


\section{Background}

Candida auris is a recently emerging nosocomial pathogen which was initially described in Japan in 2009 and then reported in over 30 countries worldwide afterwards $[1,2]$. C. auris is usually resistant to several drugs, such as fluconazole, voriconazole, amphotericin B. However, resistance rate varies between studies. According to the genome sequences, $C$. auris isolates were divided into four clades that were separated by tens of thousands of SNPs: Clade I (South Asian), Clade II (East Asian), Clade III (South African), Clade IV (South American) [3]. Besides, a potential Clade V was found in Iran recently [4].

$C$. auris can infect or colonize in humans, especially the low-immunity patients in the intensive care unit. Infection and colonization of $C$. auris are associated with varied treatment strategies and clinical outcomes, so they should be differentiated. Blood stream infections (BSI) are the most common infections with serious outcomes. Overall mortality of $C$. auris and that for patients with BSI may be as high as 59 and $68 \%$ respectively [3]. Nevertheless, other studies reported different data.

Due to its transmissibility, multidrug resistance and severe outcomes, C. auris is called "superbug fungus". Due to the low incidence of $C$. auris, no large-scale epidemiology studies were reported by now. Therefore, a comprehensive study was needed to summarize the global epidemiology of $C$. auris. In this present study, we performed a systematic review and meta-analysis to estimate the case count, drug resistance and mortality of $C$. auris. Moreover, factors that may affect the mortality such as BSI, clade and drug resistant patterns of $C$. auris were also analyzed.

\section{Methods}

\section{Search strategies and study selection}

This systematic review and meta-analysis was carried out according to Preferred Reporting Items for Systematic Reviews and Meta-Analyses (PRISMA) guidelines. We systematically searched Pubmed, Embase and Cochrane databases from inception until October 6, 2019 with the only keyword "Candida auris". Additional studies were obtained by screening the references of eligible studies. Besides, we also searched the websites of Centers for Disease Control and Prevention (CDC), European Centers for Disease Control and Prevention (ECDC) and Public Health England (PHE). Three objectives of this study were case count, drug resistance and mortality of $C$. auris. Since CDC has established breakpoints for fluconazole, amphotericin B, caspofungin, micafungin and anidulafungin in $C$. auris (fluconazole $\geq 32$, amphotericin $\mathrm{B} \geq 2$, anidulafungin $\geq 4$, caspofungin $\geq 2$ and micafungin $\geq 4$ deemed to be drug-resistant), only these drugs were analyzed in this present study.

\section{Inclusion and exclusion criteria}

All study formats met the following criteria were included in the meta-analysis: 1) Studies that reported the information of case count, drug resistance and mortality of $C$. auris, with no limit regarding the diagnostic test used for detecting C. auris. 2) Studies that provided the case count of patients with $C$. auris, number of resistant isolates/total number of $C$. auris isolates, number of deaths/total number of cases; 3) Studies with sample size larger than 5 for meta-analysis of drug resistance and mortality. While studies met the following criteria were excluded from the analysis: 1) Duplicate studies contained the same patients; 2) For meta-analysis of drug resistance of $C$. auris, studies of which the drug resistance data can't be reinterpreted according to the CDC breakpoints.

\section{Data extraction}

Title and abstract review of all searched articles was completed by two of the authors (Jingjing Chen and Sufei Tian) to identify relevant studies on the clinical report of C. auris. Then full texts of relevant articles were independently reviewed by two of the authors (Xiaoxu Han and Sufei Tian) to determine eligible studies by research objectives. Data in the articles were collected with a standardized form by two of the authors (Jingjing Chen and Xiaoxu Han) independently. Disagreements were discussed by three authors to reach consensus. The following information was extracted: first author's name, publication year, country, research time, study design, clade, case count, sample type, mortality, drug resistance patterns, methods of drug resistance methods. Drug resistant data were reinterpreted according to the CDC breakpoints.

Quality of the studies included for mortality and drug resistance analysis were assessed by the Agency for Healthcare Research and Quality (AHRQ) checklist (https://www.ncbi.nlm.nih.gov/books/NBK35156/). This 11-item checklist assesses studies in terms of the source of information, inclusion and exclusion criteria, selection of participants, researcher bias, quality assurance, possible confounding variables, handling of missing data, participant response rates, and completeness of data collection. An item would be scored " 1 " for "YES" and scored "0" for "NO" or "UNCLEAR". Article quality was classified as follows: low quality $=0-3$; moderate quality $=4-7$; high quality $=8-11$.

\section{Statistical analysis}

The pooled estimate and corresponding 95\% confidence interval (CI) were calculated with STATA11.0 software. Statistical heterogeneity was evaluated with Q statistic $(p<0.10$ indicating statistically significance) and quantified using the $\mathrm{I}^{2}$ index. Due to the heterogeneity among 
studies, all pooled estimates were performed with random-effects model. Furthermore, we did subgroup analyses for mortality stratified by continents, publication year / research year, clade of $C$. auris, sample type (BSI and non-BSI) and drug resistance rate (higher than overall estimate and lower than overall estimate). Moreover, meta-regression was performed to assess risk factors associated with mortality, with variables such as bloodstream infection, clade, fluconazole resistance, amphotericin B resistance, continent, and publication year included into the analysis. Sensitivity analysis was also performed by omission of studies. Begg's and Egger's tests were used to assess publication bias, with $p<0.05$ deemed as statistically significant.

\section{Results}

\section{Search and identification of eligible studies}

As shown in Figure S1, a total of 577 citations were obtained according to the designed search strategy as described in methods. Among them, 97 eligible articles on the clinical report of $C$. auris were selected for further evaluation and 67 studies were included in the metaanalysis. Finally, 57, 21 and 19 studies were enrolled in the analysis for case count, drug resistance and mortality of $C$. auris respectively $[1,4-67]$.

The publication year of eligible studies ranged from 2009 to 2019. Most studies were observational studies except for two studies which were case-control studies $[14,26]$. Detailed characteristics of the eligible articles were summarized in Table S1. The mean quality score of the studies included in the meta-analysis for mortality and drug resistance patterns was 6.2 (range: 4-9), with only one high quality study (Table S2). The main problems of the included articles were lack of information on quality assurance, possible confounding variables, handling of missing data, and completeness of data collection.

\section{Case count and clade of $C$. auris}

A total of 4733 cases of $C$. auris were reported in 33 countries (aligning in descending order: South Africa, United States of America, India, Spain, United Kingdom, South Korea, Colombia, Pakistan, Kenya, Kuwait, China, Russia, Venezuela, Japan, Panama, Israel, Oman, Germany, Brazil, Saudi Arabia, Singapore, France, Australia, Malaysia, Netherlands, Belgium, Norway, Switzerland, United Arab Emirates, Canada, Iran, Greece and Italy) from six continents. The earliest report was in 2009 in Japan, and the earliest isolate of C. auris traced back to 1996 in South Korea as showed by several screening experiments $[16,68]$. Moreover, an epidemic curve which depicted the case count of $C$. auris by detection year was drawn with studies that contained the detailed information. Notably, this was based on publication data rather than surveillance data. It showed that most cases were detected between 2013 and 2019, peaking in 2016 and decreasing thereafter.

Different clades of $C$. auris were reported to emerge simultaneously from different continents. Four clades of C. auris have unique geographical characteristics. Clade I was mainly reported in India, Pakistan, Kuwait, Russia, United States, United Kingdom, Germany, Malaysia, Netherlands, Italy, etc.; And Clade II were mainly in Japan and South Korea. Clade III was mainly found in South Africa, United States, United Kingdom and China, whereas Clade IV mainly distributed in Colombia and Venezuela. Clade I and III were the most prevalent clades which have more reported cases and wider geographical distribution. The case count and clade of $C$. auris stratified by country were shown in Fig. 1 .

\section{Blood stream infection of $C$. auris}

Infection and colonization of $C$. auris should be differentiated due to varied clinical significance. However, it is difficult to perform due to unavailable data in the original studies. Therefore, rate of BSI which is the most common and serious infection is analyzed instead. Studies enrolled only the candidaemia patients of $C$. auris were excluded. As shown in Fig. 2a, the frequency of BSI of $C$. auris varied between studies [25, 36, 37], with a pooled rate of blood stream infection of $32 \%$ (95\% CI: $21-42 \%)$. However, heterogeneity $\left(p=0.00, \mathrm{I}^{2}=98.7 \%\right)$ was observed between studies. Subgroup analysis showed that Clade I and Clade IV of C. auris has a high percentage of BSI compared to Clade II and Clade III (Fig. 2b). It is worth mentioning that Clade II has a low rate of BSI rate with ear discharge as the main specimen type, which is different from the other clades of $C$. auris $[9,17,69]$.

\section{Drug resistance patterns}

Meta-analyses of drug resistance were performed with data obtained according to the breakpoints for $C$. auris established by CDC. As shown in Fig. 3, the pooled resistance rate for fluconazole and amphotericin B were 91\% (95\% CI: $88-95 \%)$ and 12\% (95\% CI: 7-17\%) respectively. Yet there was significant heterogeneity between studies. Besides, publication bias was observed for meta-analysis of resistance rate for fluconazole (Figure S2), yet trim and fill method did not get good result.

Meta-analyses for the resistance rate to echinocandins could not be performed as resistance for these drugs are rare in C. auris. Descriptive analysis was performed alternatively with frequencies of resistant isolates divided by total isolates. Therefore, resistance rate to caspofungin, micafungin and anidulafungin in $C$. auris were $12.1 \%(\mathrm{n} / N=101 / 838), 0.8 \%(\mathrm{n} / N=8 / 927)$ and $1.1 \%(\mathrm{n} /$ $N=9 / 840)$ respectively. However, almost all isolates resistant to caspofungin were from India, with resistance 


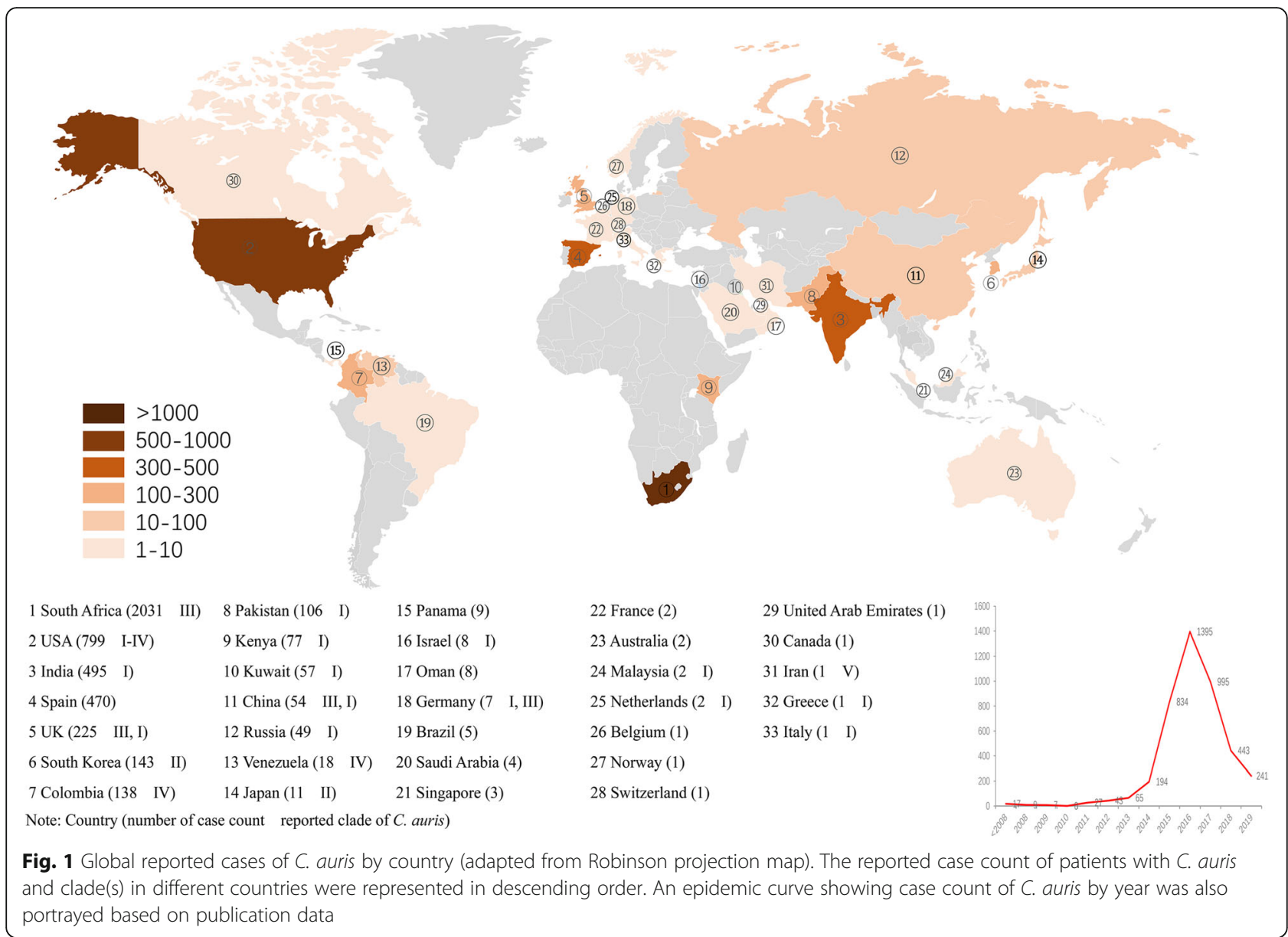

rate of $23.6 \%(\mathrm{n} / N=100 / 424)$ for Indian isolates and $0.2 \%(\mathrm{n} / \mathrm{N}=1 / 414)$ for non-Indian isolates.

\section{Mortality of C. auris}

The overall crude mortality of $C$. auris ranged from 0 to $78 \%$, with a pooled crude mortality of $39 \%$ (95\% CI: $32-$ $47 \%$, Fig. 4). While the mortality for BSI of C. auris was 45\% (95\% CI: $39-51 \%$, Figure S3). Negligible publication bias and significant heterogeneity $\left(p<0.05 ; I^{2}=72 \%\right)$ was observed. Sensitivity analysis indicated that the pooled estimate was quite stable when excluding any of the studies.

Then subgroup analyses were performed to assess factors that may influence the mortality of $C$. auris, such as continent, publication year, clade of C. auris, BSI, and resistance to fluconazole, amphotericin B (Table 1). For the subgroup analysis by clade, as most studies contained patients infected with $C$. auris of Clade I, so we stratified the studies as Clade I and non-Clade I, which showed no significant difference. Studies with $C$. auris of Clade II were not included in this analysis as lack of data which may be due to rare death. Notably, mortality of patients with BSI of $C$. auris (45, 95\% CI: 39-51\%) was higher than that in non-BSI patients (21, 95\% CI: 8-33\%). Besides, mortality of C. auris in Europe (20, 95\% CI: 4-37\%) was lower than that in Asia (44, 95\% CI: 38-51\%). However, we did not find associations between mortality and resistance to fluconazole, amphotericin B, clade or publication year.

\section{Discussion}

C. auris is a globally spreading yeast with more than 4733 cases reported by now, covering at least 33 countries from six continents. It showed $91 \%$ resistance to fluconazole, $12 \%$ resistance to amphotericin $\mathrm{B}, 12 \%$ resistance to caspofungin and were highly sensitive to micafungin and anidulafungin. The pooled crude mortality of C. auris was 39\%, while the mortality of BSI was $45 \%$. Subgroup analyses showed that cases of BSI and from Europe were factors that affected the mortality. This study is helpful for the surveillance and clinical management of $C$. auris.

Although a simple meta-analysis of $C$. auris was performed previously [70], we comprehensively described the epidemic situation and mortality of $C$. auris. 


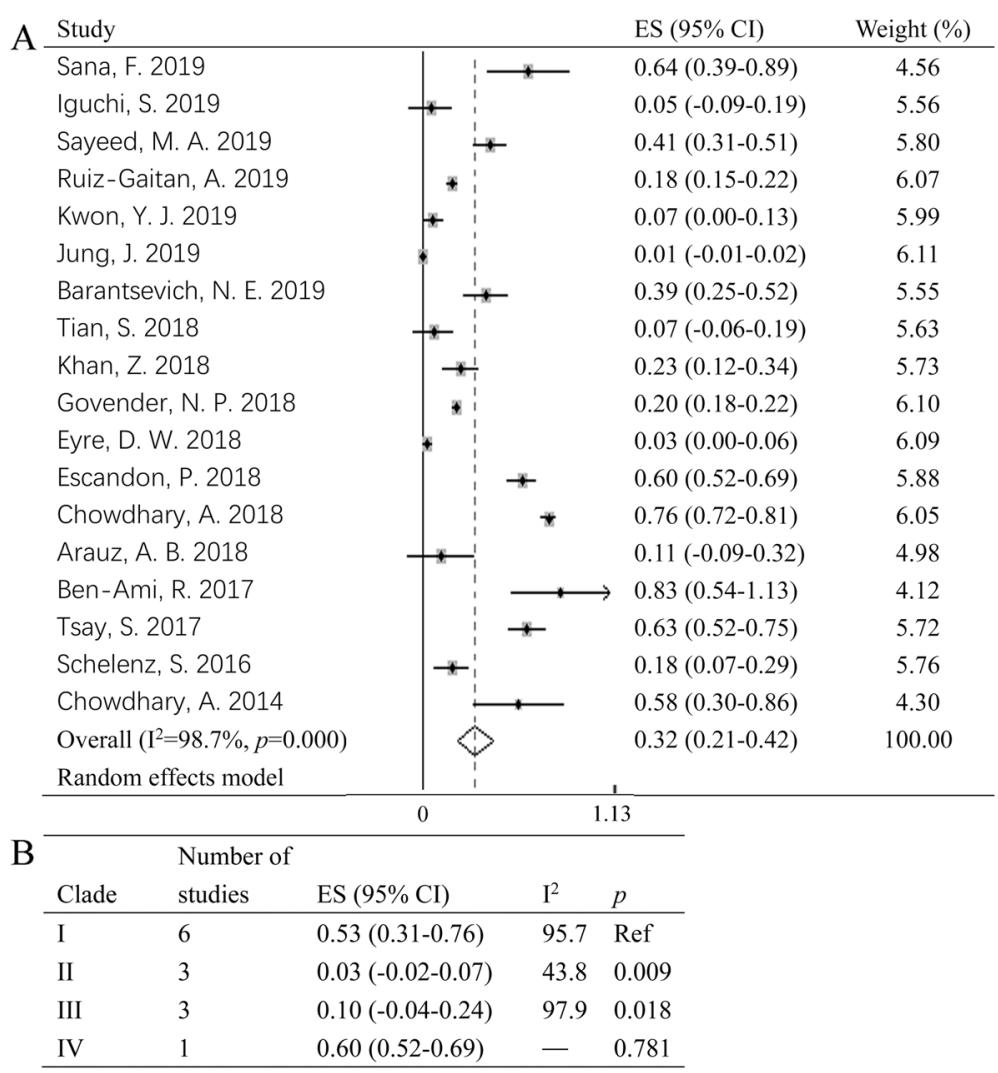

Fig. 2 Forest plot on BSI rate of C. auris (a) and subgroup analysis by clade (b). ES: Effect size

Referring to the epidemic situation of $C$. auris, over 4733 cases from 33 countries were reported. However, the actual number of cases was underreported in this study. There may be publication bias and bias based on type of surveillance conducted. First of all, there are countries with $C$. auris cases but not published in literature, such as Thailand, Chile and Bangladesh, Austria and Costa Rica [52, 71]. Secondly, there is bias based on type of surveillance conducted, as screening for $C$. auris may not be adequate in some countries. For instance, although many cases were reported in South Africa and Kenya, the other underdeveloped countries in Africa did not report cases of $C$. auris. Moreover, many patients colonized with $C$. auris which are difficult to identify may be overlooked [9]. This indicates that more intensive surveillance is needed to better understand its epidemic situation. An epidemic curve was drawn using studies with detection time, which showed a peak in 2016 and a fall thereafter. Whether this was a true reduction in case count or a delay in case report needs further follow-up.

As for the clade of C. auris, Clade I and Clade III are the geographically prevalent clade, whereas Clade II and Clade VI showed local epidemic. Besides, we found that Clade I and Clade VI of $C$. auris exhibits high BSI rate in comparison with the other clades, which was deemed as severe disease with high mortality. Whether this difference was due to specific genetic features deserves further exploration. Furthermore, as there are genes for mating and meiosis in $C$. auris, sexual recombination can occur with frequent travelling of people with $C$. auris. Consequently, the genome of $C$. auris may become more complicated.

In addition, antifungal resistance patterns were also analyzed. Resistance rate of $C$. auris to fluconazole, amphotericin B, caspofungin, micafungin and anidulafungin were $91,12,12.1,0.8$ and $1.1 \%$ respectively. It was surprising that Indian isolates showed a resistance rate of $23.6 \%$ for caspofungin, which deserves the attention of the clinicians but also needs further validation. Like the other species in the Metschnikowiaceae family (such as C. haemulonii), antifungal resistance is common in $C$. auris, limiting the treatment options. Acquired resistance through treatment is another concern which deserves clinicians' attention and further study [5]. Mutations in ERG11 (Y132F, K143R and F126L) and FKS1 (S639F) play an important role in the drug resistance of fluconazole and echinocandins, which should be detected to guide clinical treatment [72]. Drug resistance to amphotericin B may be inducible and transient, nonetheless the 


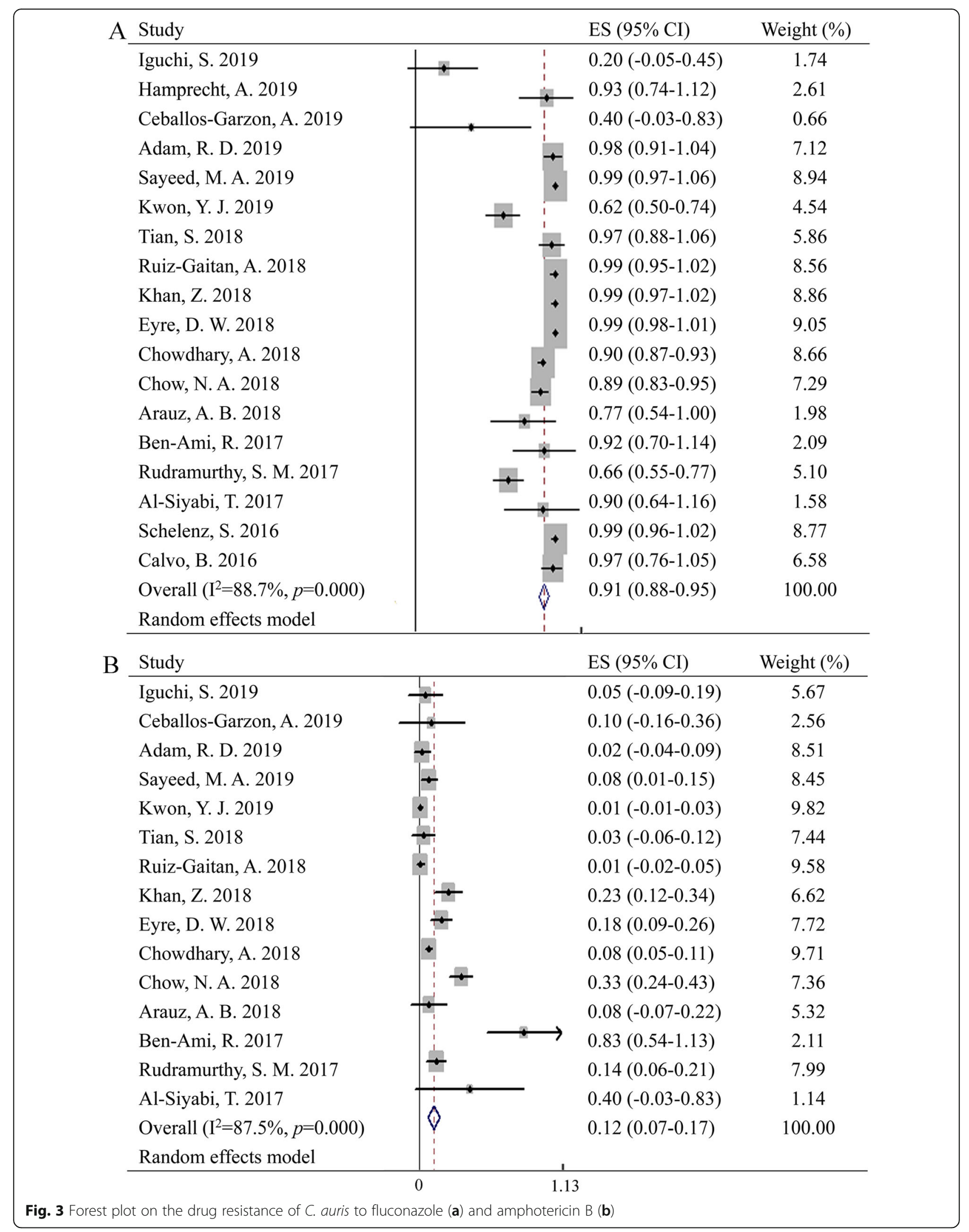




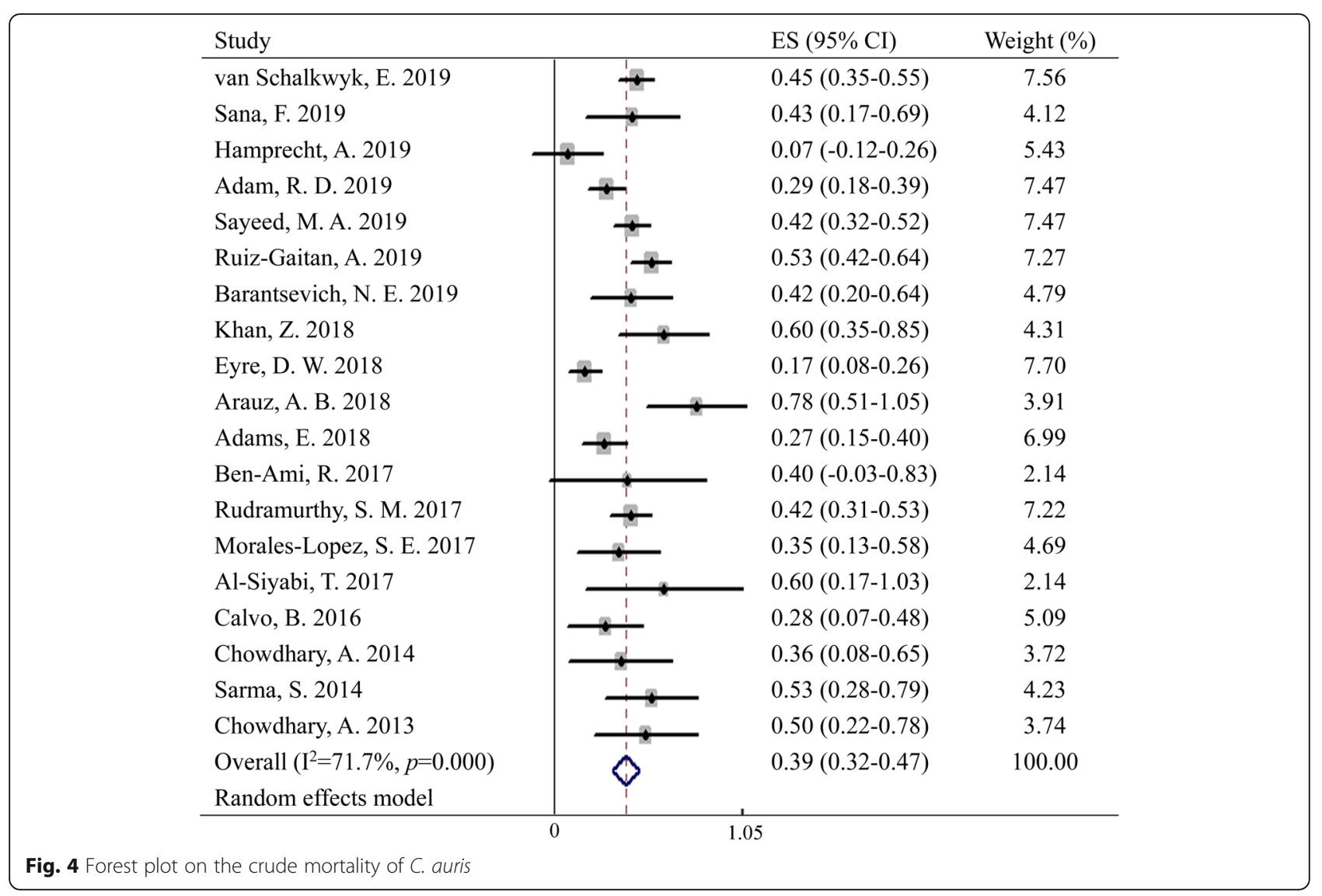

Table 1 Subgroup analyses of pooled mortality

\begin{tabular}{|c|c|c|c|c|c|}
\hline Factors & Group & Number of studies & Pooled crude mortality $(95 \% \mathrm{Cl})$ & $I^{2}(\%)$ & $p$ value \\
\hline \multirow[t]{2}{*}{ Bloodstream infection } & Yes & 15 & $0.45(0.39-0.51)$ & 41 & 0.002 \\
\hline & No & 5 & $0.21(0.08-0.33)$ & 40 & Ref \\
\hline \multirow[t]{2}{*}{ Clade } & Clade I & 11 & $0.39(0.31-0.47)$ & 49 & 0.343 \\
\hline & Non- Clade I & 4 & $0.31(0.14-0.48)$ & 83 & Ref \\
\hline \multirow[t]{2}{*}{ FLC resistance } & Higher & 10 & $0.29(0.21-0.38)$ & 60 & 0.415 \\
\hline & Lower & 3 & $0.49(0.29-0.70)$ & 70 & Ref \\
\hline \multirow[t]{2}{*}{ AmB resistance } & Higher & 6 & $0.29(0.19-0.40)$ & 45 & 0.159 \\
\hline & Lower & 6 & $0.43(0.32-0.53)$ & 62 & Ref \\
\hline \multirow[t]{4}{*}{ Continent } & Asia & 9 & $0.44(0.38-0.51)$ & 0 & 0.000 \\
\hline & America & 5 & $0.43(0.27-0.59)$ & 78 & 0.164 \\
\hline & Africa & 2 & $0.37(0.21-0.53)$ & 81 & 0.303 \\
\hline & Europe & 3 & $0.20(0.04-037)$ & 66 & Ref \\
\hline \multirow[t]{3}{*}{ Publication Year } & 2018-2019 & 11 & $0.42(0.31-0.53)$ & 86 & 0.769 \\
\hline & 2016-2017 & 5 & $0.39(0.30-0.48)$ & 0 & 0.415 \\
\hline & 2013-2015 & 3 & $0.47(0.31-0.63)$ & 0 & Ref \\
\hline
\end{tabular}


mechanisms are not well understood yet. Moreover, genomic insights and analyses of gene expression showed that genes associated with oligopeptide and $A B C$ transporters, iron transporters, glycophosphatidylinositol-anchored proteins, etcmay be involved in drug resistance of $C$. auris [73, 74].

The pooled crude mortality of C. auris infection was $39 \%$, with an overall mortality of BSI of $45 \%$. Previous meta-analysis indicated that the mortality of candidemia in Europe was 38\% [75]. Moreover, the mortality of C. auris was also compared with other drug-resistant organisms, which spread in similar ways in healthcare centers. A metaanalysis showed that the mortality of patients infected with multidrug-resistant Pseudomonas aeruginosa was 44.6\% [76]. Besides, the overall mortality of BSIs of vancomycin resistant Staphylococcus aureus and carbapenem-resistant Klebsiella pneumoniae were 26.8 and $54.3 \%$ respectively $[77,78]$. This indicates that the mortality of $C$. auris candidemia was a little higher than the other candidemia and similar to that of some drug-resistant bacterial BSIs.

There was heterogeneity between studies, so we investigated factors that may affect the mortality of C. auris infection, such as clade, BSI, drug resistance, continent and publication year. Results showed that the mortality of BSI of $C$. auris was higher than that of non-BSI. Besides, the mortality reported in Europe was lower than that in Asia. This indicated that types of infection and continent were factors for significant heterogeneity. In addition, mortality at any time rather than 30-day mortality, clades of $C$. auris, study designs may be the causes of heterogeneity. Reasons explaining for lower mortality in Europe may be as follows: (1) high percentage of non-BSI [10, 19, 26]; (2) better healthcare systems in developed countries with more intensive surveillance and rational treatment.

Although this study was a comprehensive analysis, some limitations should be noted. Firstly, there was an underestimation in case count of $C$. auris due to publication bias and bias based on type of surveillance conducted. What's more, most studies included were observational studies, crude mortality rather than attributable mortality was analyzed. Furthermore, significant heterogeneity was observed between studies, well-designed case-control studies should be carried out to estimate the resistance patterns and mortality of $C$. auris accurately.

C. auris is an emerging pathogen covering over 33 countries, which may have a decrease in case count after 2016. It showed high resistance to fluconazole, moderate resistance to amphotericin B, and high sensitivity to echinocandins. The crude mortality for BSI of $C$. auris was $45 \%$ which was similar to some drug-resistant bacteria previously reported. In summary, $C$. auris displayed similar characteristics to some drug resistance organisms. C. auris may not be so scary, yet it should not be underestimated, intensive prevention and control should be taken.

\section{Supplementary Information}

The online version contains supplementary material available at https://doi. org/10.1186/s12879-020-05543-0.

Additional file 1: Table S1 Characteristics of included studies.

Additional file 2: Table S2 Quality assessment of the studies included in the meta-analysis for mortality and drug resistance patterns.

Additional file 3: Figure S1 Flowchart showing study search and selection.

Additional file 4: Figure S2 Funnel plot for BSI rate of $C$. auris (A), drug resistance of $C$. auris to fluconazole $(B)$ and amphotericin $B(C)$, crude mortality (D).

Additional file 5: Figure S3 Forest plot on the crude mortality for BS of C. auris.

Abbreviations

BSI: Bloodstream infections; CDC: Centers for Disease Control and Prevention; ECDC: European Centers for Disease Control and Prevention; PHE: Public Health England; AHRQ: Agency for Healthcare Research and Quality;

$\mathrm{Cl}$ : Confidence interval

\section{Acknowledgments}

We appreciate Katie Forsberg from the CDC for providing additional information on the case count of $C$. auris.

\section{Authors' contributions}

$\mathrm{SH}, \mathrm{HX}$ and $\mathrm{CJ}$ conceived and designed the study. CJ and TS performed title and abstract review of studies, HX and TS reviewed relevant articles for eligibility. Data were collected and analyzed by CJ, WQ, ZB and HX. CJ, TS, $\mathrm{CY}$ and $\mathrm{HX}$ wrote the manuscript. All authors read and approved the final manuscript.

\section{Funding}

This work was supported by Laboratory medicine innovation unit, Chinese Academy of Medical Sciences (2019RU017) and National Key Specialist Construction Project for Clinical Laboratory Medicine.

Availability of data and materials

The datasets used and/or analyzed of the current study are available from the corresponding author on request.

Ethics approval and consent to participate

Not Applicable.

Consent for publication

Not Applicable.

\section{Competing interests}

The authors declare that they have no conflicts of interest.

\section{Author details}

${ }^{1}$ Department of Laboratory Medicine, the First Affiliated Hospital of China Medical University, No. 155, Nanjing North Street, Heping District, Shenyang 110001, Liaoning, China. ${ }^{2}$ National Clinical Research Center for Laboratory Medicine, the First Affiliated Hospital of China Medical University, Shenyang 110001, China. ${ }^{3}$ Collaborative Innovation Center for Diagnosis and Treatment of Infectious Diseases, 79 Qingchun Street, Hangzhou 310003, China. ${ }^{4}$ Department of Clinical Epidemiology and Center of Evidence-Based Medicine, the First Hospital of China Medical University, Shenyang 110001, China.

Received: 10 October 2019 Accepted: 26 October 2020

Published online: 11 November 2020

\section{References}

1. Satoh K, Makimura K, Hasumi Y, Nishiyama Y, Uchida K, Yamaguchi H. Candida auris sp. nov., a novel ascomycetous yeast isolated from the external ear canal of an inpatient in a Japanese hospital. Microbiol Immunol. 2009;53(1):41-4 
2. Rhodes J, Fisher MC. Global epidemiology of emerging Candida auris. Curr Opin Microbiol. 2019;52:84-9.

3. Lockhart SR, Etienne KA, Vallabhaneni S, Faroogi J, Chowdhary A, Govender $\mathrm{NP}$, et al. Simultaneous emergence of multidrug-resistant Candida auris on 3 continents confirmed by whole-genome sequencing and epidemiological analyses. Clin Infect Dis. 2017;64(2):134-40.

4. Chow NA, Gade L, Tsay SV, Forsberg K, Greenko JA, Southwick KL, et al. Multiple introductions and subsequent transmission of multidrug-resistant Candida auris in the USA: a molecular epidemiological survey. Lancet Infect Dis. 2018:18(12):1377-84.

5. Biagi MJ, Wiederhold NP, Gibas C, Wickes BL, Lozano V, Bleasdale SC, et al. Development of High-Level Echinocandin Resistance in a Patient With Recurrent Candida auris Candidemia Secondary to Chronic Candiduria. Open Forum Infect Dis. 2019;6(7):ofz262.

6. van Schalkwyk E, Mpembe RS, Thomas J, Shuping L, Ismail H, Lowman W, et al. Epidemiologic shift in Candidemia driven by Candida auris, South Africa, 2016-2017(1). Emerg Infect Dis. 2019;25(9):1698-707.

7. Chibabhai V, Fadana V, Bosman N, Nana T. Comparative sensitivity of 1,3 beta-D-glucan for common causes of candidaemia in South Africa. Mycoses. 2019;62(11):1023-8.

8. Sana F, Hussain W, Zaman G, Satti L, Khurshid U, Khadim MT. Candida auris associated outbreak report from Pakistan: a success story of infection control in ICU of a tertiary care hospital. J Hosp Infect. 2019;103(1):108-10.

9. Iguchi S, Itakura Y, Yoshida A, Kamada K, Mizushima R, Arai Y, et al. Candida auris: a pathogen difficult to identify, treat, and eradicate and its characteristics in Japanese strains. J Infect Chemother. 2019;25(10):743-9.

10. Hamprecht A, Barber AE, Mellinghoff SC, Thelen P, Walther G, Yu Y, et al. Candida auris in Germany and Previous Exposure to Foreign Healthcare. Emerg Infect Dis. 2019;25(9):1763-5.

11. Ceballos-Garzon A, Cortes G, Morio F, Zamora-Cruz EL, Linares MY, Ariza BE, et al. Comparison between MALDI-TOF MS and MicroScan in the identification of emerging and multidrug resistant yeasts in a fourth-level hospital in Bogota, Colombia. BMC Microbiol. 2019;19(1):106.

12. Adam RD, Revathi G, Okinda N, Fontaine M, Shah J, Kagotho E, et al. Analysis of Candida auris fungemia at a single facility in Kenya. Int J Infect Dis. 2019;85:182-7.

13. Sayeed MA, Farooqi J, Jabeen K, Awan S, Mahmood SF. Clinical spectrum and factors impacting outcome of Candida auris: a single center study from Pakistan. BMC Infect Dis. 2019;19(1):384.

14. Ruiz-Gaitan A, Martinez H, Moret AM, Calabuig E, Tasias M, AlastrueyIzquierdo $A$, et al. Detection and treatment of Candida auris in an outbreak situation: risk factors for developing colonization and candidemia by this new species in critically ill patients. Expert Rev Anti-Infect Ther. 2019;17(4): 295-305.

15. Park JY, Bradley N, Brooks S, Burney S, Wassner C. Management of patients with Candida auris Fungemia at community hospital, Brooklyn, New York, USA, 2016-2018(1). Emerg Infect Dis. 2019;25(3):601-2.

16. Kwon YJ, Shin JH, Byun SA, Choi MJ, Won EJ, Lee D, et al. Candida auris Clinical Isolates from South Korea: Identification, Antifungal Susceptibility, and Genotyping. J Clin Microbiol. 2019;57(4):e01624-18.

17. Jung J, Kim MJ, Kim JY, Lee JY, Kwak SH, Hong MJ, et al. Candida auris colonization or infection of the ear: A single-center study in South Korea from 2016 to 2018. Med Mycol. 2019;58(1):124-7.

18. Escandon P, Chow NA, Caceres DH, Gade L, Berkow EL, Armstrong P, et al. Molecular epidemiology of Candida auris in Colombia reveals a highly related, countrywide colonization with regional patterns in amphotericin B resistance. Clin Infect Dis. 2019;68(1):15-21.

19. Barantsevich NE, Orlova OE, Shlyakhto EV, Johnson EM, Woodford N, LassFloerl C, et al. Emergence of Candida auris in Russia. J Hosp Infect. 2019; 102(4):445-8.

20. Tian S, Rong C, Nian H, Li F, Chu Y, Cheng S, et al. First cases and risk factors of super yeast Candida auris infection or colonization from Shenyang, China. Emerg Microbes Infect. 2018;7(1):128.

21. Ruiz-Gaitan A, Moret AM, Tasias-Pitarch M, Aleixandre-Lopez Al, Martinez Morel H, Calabuig E, et al. An outbreak due to Candida auris with prolonged colonisation and candidaemia in a tertiary care European hospital. Mycoses. 2018;61(7):498-505.

22. Kohlenberg A, Struelens MJ, Monnet DL, Plachouras D. Candida auris: epidemiological situation, laboratory capacity and preparedness in European Union and European Economic Area countries, 2013 to 2017. Euro Surveillance. 2018;23(13):18-00136.
23. Khan Z, Ahmad S, Al-Sweih N, Joseph L, Alfouzan W, Asadzadeh M. Increasing prevalence, molecular characterization and antifungal drug susceptibility of serial Candida auris isolates in Kuwait. PLoS One. 2018;13(4): e0195743.

24. Khan Z, Ahmad S, Benwan K, Purohit P, Al-Obaid I, Bafna R, et al. Invasive Candida auris infections in Kuwait hospitals: epidemiology, antifungal treatment and outcome. Infection. 2018;46(5):641-50.

25. Govender NP, Magobo RE, Mpembe R, Mhlanga M, Matlapeng P, Corcoran C, et al. Candida auris in South Africa, 2012-2016. Emerg Infect Dis. 2018; 24(11):2036-40.

26. Eyre DW, Sheppard AE, Madder H, Moir I, Moroney R, Quan TP, et al. A Candida auris outbreak and its control in an intensive care setting. N Engl J Med. 2018:379(14):1322-31.

27. Escandon $P$, Caceres DH, Espinosa-Bode A, Rivera S, Armstrong P, Vallabhaneni $S$, et al. Notes from the field: surveillance for Candida auris Colombia, September 2016-may 2017. MMWR Morb Mortal Wkly Rep. 2018; 67(15):459-60.

28. Chowdhary A, Prakash A, Sharma C, Kordalewska M, Kumar A, Sarma S, et al. A multicentre study of antifungal susceptibility patterns among 350 Candida auris isolates (2009-17) in India: role of the ERG11 and FKS1 genes in azole and echinocandin resistance. J Antimicrob Chemother. 2018;73(4):891-9.

29. Arauz AB, Caceres DH, Santiago E, Armstrong P, Arosemena S, Ramos $C$, et al. Isolation of Candida auris from 9 patients in Central America: importance of accurate diagnosis and susceptibility testing. Mycoses. 2018; 61(1):44-7.

30. Adams E, Quinn M, Tsay S, Poirot E, Chaturvedi S, Southwick K, et al. Candida auris in healthcare facilities, New York, USA, 2013-2017. Emerg Infect Dis. 2018;24(10):1816-24

31. Ben-Ami R, Berman J, Novikov A, Bash E, Shachor-Meyouhas Y, Zakin S, et al. Multidrug-Resistant Candida haemulonii and C. auris, Tel Aviv, Israel. Emerg Infect Dis. 2017;23(1):195-203.

32. Rudramurthy SM, Chakrabarti A, Paul RA, Sood P, Kaur H, Capoor MR, et al. Candida auris candidaemia in Indian ICUs: analysis of risk factors. J Antimicrob Chemother. 2017;72(6):1794-801.

33. Morales-Lopez SE, Parra-Giraldo CM, Ceballos-Garzon A, Martinez HP, Rodriguez GJ, Alvarez-Moreno CA, et al. Invasive infections with multidrugresistant yeast Candida auris, Colombia. Emerg Infect Dis. 2017;23(1):162-4.

34. Al-Siyabi T, Al Busaidi I, Balkhair A, Al-Muharrmi Z, Al-Salti M, Al'Adawi B. First report of Candida auris in Oman: clinical and microbiological description of five candidemia cases. J Infect. 2017;75(4):373-6.

35. Schelenz S, Hagen F, Rhodes JL, Abdolrasouli A, Chowdhary A, Hall A, et al. First hospital outbreak of the globally emerging Candida auris in a European hospital. Antimicrob Resist Infect Control. 2016;5:35.

36. Prakash A, Sharma C, Singh A, Kumar Singh P, Kumar A, Hagen F, et al. Evidence of genotypic diversity among Candida auris isolates by multilocus sequence typing, matrix-assisted laser desorption ionization time-of-flight mass spectrometry and amplified fragment length polymorphism. Clin Microbiol Infect. 2016;22(3):277 e1-9.

37. Calvo B, Melo AS, Perozo-Mena A, Hernandez M, Francisco EC, Hagen F, et al. First report of Candida auris in America: clinical and microbiological aspects of 18 episodes of candidemia. J Infect. 2016;73(4):369-74.

38. Chowdhary A, Anil Kumar V, Sharma C, Prakash A, Agarwal K, Babu R, et al. Multidrug-resistant endemic clonal strain of Candida auris in India. Eur J Clin Microbiol Infect Dis. 2014;33(6):919-26.

39. Sarma S, Kumar N, Sharma S, Govil D, Ali T, Mehta Y, et al. Candidemia caused by amphotericin B and fluconazole resistant Candida auris. Indian J Med Microbiol. 2013;31(1):90-1.

40. Chowdhary A, Sharma C, Duggal S, Agarwal K, Prakash A, Singh PK, et al. New clonal strain of Candida auris, Delhi, India. Emerg Infect Dis. 2013; 19(10):1670-3.

41. Ding CH, Situ SF, Steven A, Razak MFA. The pitfall of utilizing a commercial biochemical yeast identification kit to detect Candida auris. Ann Clin Lab Sci. 2019:49(4):546-9.

42. Crea F, Codda G, Orsi A, Battaglini A, Giacobbe DR, Delfino E, et al. Isolation of Candida auris from invasive and non-invasive samples of a patient suffering from vascular disease, Italy, July 2019. Euro surveillance. 2019; 24(37):1900549.

43. Vogelzang EH, Weersink AJL, van Mansfeld R, Chow NA, Meis JF, van Dijk K. The First Two Cases of Candida auris in The Netherlands. J Fungi (Basel, Switzerland). 2019;5(4):91. 
44. Supreeth S, Al Ghafri KA, Kumar JR, Al Balushi ZY. First report of Candia auris spondylodiscitis in Oman - A rare presentation. World Neurosurg. 2019;135:335-8.

45. Stathi A, Loukou I, Kirikou H, Petrocheilou A, Moustaki M, Velegraki A, et al. Isolation of Candida auris from cystic fibrosis patient, Greece, April 2019. Euro Surveillance. 2019:24(29):1900400.

46. Elsawy A, Alquthami K, Alkhutani N, Marwan D, Abbas A. The second confirmed case of Candida auris from Saudi Arabia. J Infect Public Health. 2019;12(6):907-8.

47. Tang HJ, Lai CC, Lai FJ, Li SY, Liang HY, Hsueh PR. Emergence of multidrug-resistant Candida auris in Taiwan. Int J Antimicrobial Agents. 2019;53(5):705-6.

48. O'Connor C, Bicanic T, Dave J, Evans TJ, Moxey P, Adamu U, et al. Candida auris outbreak on a vascular ward - the unexpected arrival of an anticipated pathogen. J Hosp Infect. 2019;103(1):106-8.

49. Abastabar M, Haghani I, Ahangarkani F, Rezai MS, Taghizadeh Armaki M, Roodgari $S$, et al. Candida auris otomycosis in Iran and review of recent literature. Mycoses. 2019;62(2):101-5.

50. Heath $\mathrm{CH}$, Dyer JR, Pang S, Coombs GW, Gardam DJ. Candida auris sternal osteomyelitis in a man from Kenya visiting Australia, 2015. Emerg Infect Dis. 2019;25(1):192-4.

51. Wang X, Bing J, Zheng Q, Zhang F, Liu J, Yue H, et al. The first isolate of Candida auris in China: clinical and biological aspects. Emerg Microbes Infect. 2018;7(1):93.

52. Tan YE, Tan AL. Arrival of Candida auris fungus in Singapore: report of the first 3 cases. Ann Acad Med Singap. 2018;47(7):260-2.

53. Riat A, Neofytos D, Coste A, Harbarth S, Bizzini A, Grandbastien B, et al. First case of Candida auris in Switzerland: discussion about preventive strategies. Swiss Med Wkly. 2018;148:w14622.

54. Pekard-Amenitsch S, Schriebl A, Posawetz W, Willinger B, Kolli B, Buzina W. Isolation of Candida auris from ear of otherwise healthy patient, Austria, 2018. Emerg Infect Dis. 2018;24(8):1596-7.

55. Parra-Giraldo CM, Valderrama SL, Cortes-Fraile G, Garzon JR, Ariza BE, Morio F, et al. First report of sporadic cases of Candida auris in Colombia. Int J Infect Dis. 2018;69:63-7.

56. Mohd Tap R, Lim TC, Kamarudin NA, Ginsapu SJ, Abd Razak MF, Ahmad N, et al. A fatal case of Candida auris and Candida tropicalis Candidemia in Neutropenic patient. Mycopathologia. 2018;183(3):559-64.

57. Chen Y, Zhao J, Han L, Qi L, Fan W, Liu J, et al. Emergency of fungemia cases caused by fluconazole-resistant Candida auris in Beijing, China. J Infect. 2018;77(6):561-71.

58. Belkin A, Gazit Z, Keller N, Ben-Ami R, Wieder-Finesod A, Novikov A, et al. Candida auris infection leading to nosocomial transmission, Israel, 2017. Emerg Infect Dis. 2018;24(4):801-4.

59. Alatoom A, Sartawi M, Lawlor K, AbdelWareth L, Thomsen J, Nusair A, et al. Persistent candidemia despite appropriate fungal therapy: first case of Candida auris from the United Arab Emirates. Int J Infect Dis. 2018:70:36-7.

60. Abdalhamid B, Almaghrabi R, Althawadi S, Omrani A. First report of Candida auris infections from Saudi Arabia. J Infect Public Health. 2018;11(4):598-9.

61. Schwartz IS, Hammond GW. First reported case of multidrug-resistant Candida auris in Canada. Can Commun Dis Rep. 2017:43(7-8):150-3.

62. Mohsin J, Hagen F, Al-Balushi ZAM, de Hoog GS, Chowdhary A, Meis JF, et al. The first cases of Candida auris candidaemia in Oman. Mycoses. 2017; 60(9):569-75.

63. Choi HI, An J, Hwang JJ, Moon SY, Son JS. Otomastoiditis caused by Candida auris: case report and literature review. Mycoses. 2017;60(8): 488-92.

64. Biswal M, Rudramurthy SM, Jain N, Shamanth AS, Sharma D, Jain K, et al. Controlling a possible outbreak of Candida auris infection: lessons learnt from multiple interventions. J Hosp Infect. 2017;97(4):363-70.

65. Kim TH, Kweon OJ, Kim HR, Lee MK. Identification of uncommon Candida species using commercial identification systems. J Microbiol Biotechnol. 2016;26(12):2206-13

66. Kumar D, Banerjee T, Pratap CB, Tilak R. Itraconazole-resistant Candida auris with phospholipase, proteinase and hemolysin activity from a case of vulvovaginitis. J Infect Dev Ctries. 2015;9(4):435-7.

67. Emara M, Ahmad S, Khan Z, Joseph L, Al-Obaid I, Purohit P, et al. Candida auris candidemia in Kuwait, 2014. Emerg Infect Dis. 2015;21(6):1091-2.

68. Pfaller MA, Diekema DJ, Turnidge JD, Castanheira M, Jones RN. Twenty years of the SENTRY antifungal surveillance program: results for Candida species from 1997-2016. Open Forum Infect Dis. 2019;6(Suppl 1):S79-s94.
69. Oh BJ, Shin JH, Kim MN, Sung H, Lee K, Joo MY, et al. Biofilm formation and genotyping of Candida haemulonii, Candida pseudohaemulonii, and a proposed new species (Candida auris) isolates from Korea. Med Mycol. 2011; 49(1):98-102.

70. Osei SJ. Candida auris: a systematic review and meta-analysis of current updates on an emerging multidrug-resistant pathogen. MicrobiologyOpen. 2018;7(4):e00578.

71. Lone SA, Ahmad A. Candida auris-the growing menace to global health. Mycoses. 2019;62(8):620-37.

72. Hou X, Lee A, Jimenez-Ortigosa C, Kordalewska M, Perlin DS, Zhao Y. Rapid Detection of ERG11-Associated Azole Resistance and FKS-Associated Echinocandin Resistance in Candida auris. Antimicrobial Agents Chemother. 2019;63(1):e01811-18.

73. Wasi M, Khandelwal NK, Moorhouse AJ, Nair R, Vishwakarma P, Bravo Ruiz G, et al. $A B C$ transporter genes show Upregulated expression in drug-resistant clinical isolates of Candida auris: a genome-wide characterization of ATPbinding cassette (ABC) transporter genes. Front Microbiol. 2019;10:1445.

74. Munoz JF, Gade L, Chow NA, Loparev VN, Juieng P, Berkow EL, et al. Genomic insights into multidrug-resistance, mating and virulence in Candida auris and related emerging species. Nat Commun. 2018;9(1):5346.

75. Koehler P, Stecher M, Cornely OA, Koehler D, Vehreschild M, Bohlius J, et al. Morbidity and mortality of candidaemia in Europe: an epidemiologic metaanalysis. Clin Microbiol Infect. 2019;25(10):1200-12.

76. Matos ECO, Andriolo RB, Rodrigues YC, Lima PDL, Carneiro I, Lima KVB. Mortality in patients with multidrug-resistant Pseudomonas aeruginosa infections: a meta-analysis. Rev Soc Bras Med Trop. 2018:51(4):415-20.

77. Xu L, Sun X, Ma X. Systematic review and meta-analysis of mortality of patients infected with carbapenem-resistant Klebsiella pneumoniae. Ann Clin Microbiol Antimicrob. 2017;16(1):18.

78. Kalil AC, Van Schooneveld TC, Fey PD, Rupp ME. Association between vancomycin minimum inhibitory concentration and mortality among patients with Staphylococcus aureus bloodstream infections: a systematic review and meta-analysis. Jama. 2014;312(15):1552-64.

\section{Publisher's Note}

Springer Nature remains neutral with regard to jurisdictional claims in published maps and institutional affiliations.
Ready to submit your research? Choose BMC and benefit from:

- fast, convenient online submission

- thorough peer review by experienced researchers in your field

- rapid publication on acceptance

- support for research data, including large and complex data types

- gold Open Access which fosters wider collaboration and increased citations

- maximum visibility for your research: over $100 \mathrm{M}$ website views per year

At BMC, research is always in progress.

Learn more biomedcentral.com/submissions 